\title{
CrystEngComm
}

HIGHLIGHT

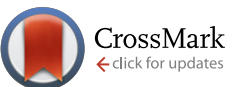

Cite this: CrystEngComm, 2016, 18, 3985

Received 23rd December 2015, Accepted 18th January 2016

DOI: $10.1039 / c 5 c e 02526 e$

www.rsc.org/crystengcomm

\section{Metal-organic frameworks (MOFs) bring new life to hydrogen-bonding organocatalysts in confined spaces}

\author{
Juan V. Alegre-Requena, ${ }^{a b}$ Eugenia Marqués-López, ${ }^{b}$ Raquel P. Herrera*b \\ and David Díaz Díaz ${ }^{\star a c}$
}

Hydrogen-bonding organocatalysis has emerged as a promising biomimetic alternative to Lewis acid catalysis. Urea, thiourea and squaramide moieties represent the most common hydrogen-bond donors used for the preparation of these catalysts. However, their significant tendency to undergo self-quenching (self-aggregation) often decreases their solubility and reactivity. Recently, scientists have found a promising way around this problem by immobilizing the hydrogen-bonding organocatalysts on metal-organic frameworks (MOFs). Along with advantageous modular synthesis and recycling properties, the tunable porosity and topology of MOFs also allows fast mass transport and/or interactions with substrates. Herein, we highlight the existing examples dealing with the fabrication and testing of hydrogen-bonding organocatalystcontaining MOFs, providing also our vision for further advances in this area. The results derived from these studies will likely serve as inspiration for the future development of superior hydrogen-bonding organocatalysts to accomplish in confined spaces chemical transformations that are either slow or unaffordable under standard homogeneous conditions.

\section{Introduction}

Most of the chemical reactions that occur in living systems are high-energy reactions that would be unaffordable or would occur very slowly without the catalysis provided by enzymes. This has inspired scientists during many decades to develop artificial catalysts ${ }^{1,2}$ within a general quest for economic profit. As a matter of fact, catalysts are nowadays the workhorses of the chemical transformations in industry ( $c a$. $85-90 \%$ of the products of the chemical industry are fabricated through catalytic processes). ${ }^{3}$ However, the increasing on-demand production of bulk chemicals, fine chemicals and fuels is also threatening the stability of the ecosystems in our planet due to environmentally harmful wastes. Thus, stricter environmental regulations by governments have motivated the replacement of numerous homogeneous reactions by greener and economical heterogeneous catalytic processes. ${ }^{4}$

Within this context, supramolecular coordination chemistry offers a promising biomimetic platform with well-defined

\footnotetext{
${ }^{a}$ Institut für Organische Chemie, Universität Regensburg, Universitätsstr. 31, 93040 Regensburg, Germany. E-mail: David.Diaz@chemie.uni-regensburg.de; Tel: + 499419434373

${ }^{b}$ Laboratorio de Organocatálisis Asimétrica, Departamento de Química Orgánica, Instituto de Síntesis Quimica y Catálisis Homogénea (ISQCH), CSIC-Universidad de Zaragoza, Pedro Cerbuna 12, 50009 Zaragoza, Spain.

E-mail: raquelph@unizar.es; Tel: +34976761190

${ }^{c}$ IQAC-CSIC, Jordi Girona 18-26, 08034 Barcelona, Spain
}

functional groups suitable for catalysis. ${ }^{5-9}$ Features such as numerous metal geometries, tunable bond directionality and self-correcting kinetic reversibility have allowed the development of a variety of metal-organic materials (MOMs) with major relevance in the field of catalysis. ${ }^{10,11}$ Among the vast field of MOMs, ${ }^{12}$ and supported by the gradual maturation of crystal engineering, ${ }^{13}$ nanoscale metal-organic frameworks (MOFs) $)^{14,15}$ have taken a pivotal role in the rational design of eco-friendly heterogeneous catalysts ${ }^{16}$ beyond their more traditional applications in gas storage and gas separation, ${ }^{17-22}$ sensing, ${ }^{23,24}$ ion exchange, ${ }^{25}$ drug delivery ${ }^{26,27}$ and light harvesting. ${ }^{28}$ MOFs are composed of inorganic nodes (metal ions or clusters) judiciously linked by polytopic functional organic struts to form uniform three-dimensional (3D) arrays of high surface area (up to $\left.10400 \mathrm{~m}^{2} \mathrm{~g}^{-1}\right),{ }^{29}$ large pores $(98 \AA)^{30}$ and low density $\left(0.13 \mathrm{~g} \mathrm{~cm}^{-3}\right) .{ }^{31}$ In general, the active sites of MOF-based catalysts can be either metal centers with unsaturated coordination environments, catalysts encapsulated in the pores or the sites inherent in the organic framework. ${ }^{32}$ Along with the advantages of their modular synthesis ${ }^{33,34}$ and recycling properties, the tunable porosity and topology of MOFs also allow fast mass transport and/or interactions with substrates. These features, often challenging in homogeneous states, differentiate MOFs from other nanoporous materials such as zeolites and activated carbons. Overall, MOFs constitute ideal candidates for heterogeneous catalysis if the framework crystallinity and regularity are retained under the 
reaction conditions or during post-synthetic modification strategies that can be used to introduce functional groups on MOFs in order to extend their catalytic activity. ${ }^{35,36}$

Despite the extensive use of MOFs in heterogeneous catalysis during the last decade, ${ }^{32,37}$ some drawbacks are usually associated to unsatisfactory yields, poor selectivities or limited substrate scope. ${ }^{37}$ Moreover, among the plethora of MOF-based catalysts, hydrogen-bonding organocatalysts ${ }^{38}$ have met MOFs only recently. Hydrogen-bonding organocatalysts have emerged as a biomimetic alternative to Lewis acid activation ${ }^{38-40}$ by means of mainly urea, thiourea or squaramide moieties. This is relevant because although a significant number of bond-forming reactions can be catalysed by homogeneous hydrogen-bonding organocatalysts, ${ }^{41}$ their tendency to undergo self-quenching (self-aggregation) often decrease their solubility and reactivity.

Herein, we highlight the recent contributions involving the fabrication and use of hydrogen-bonding organocatalysts immobilized on MOFs. We believe that these unique examples are paving the way for the development of superior hydrogen-bonding organocatalysts for complicated chemical transformations.

\section{Urea-containing MOF catalysts}

Farha, Hupp, Scheidt and co-workers reported the first ureacontaining metal-organic framework (MOF) with the idea of preventing the self-association that homogeneous catalysts, such as ureas, undergo in their reactions. This selfquenching is responsible for the consequent decrease in the solubility and reactivity of the catalysts (Fig. 1, top). ${ }^{42,43}$ For this purpose, the authors envisioned that this self-quenching may be avoided if the urea catalyst is incorporated into coordination polymers using an appropriate metal ion, which possess defined reaction environments and high porosity (Fig. 1, bottom). ${ }^{43}$

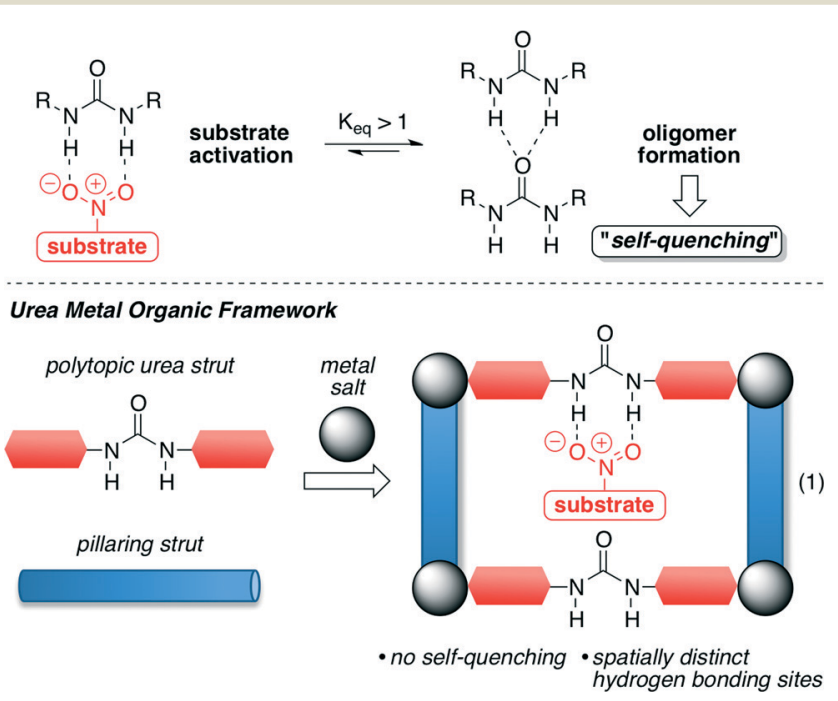

Fig. 1 Synthetic strategy of urea MOF derivatives. Adapted with permission from ref. 43. Copyright ${ }^{\circledR}$ American Chemical Society.
Based on this pioneering idea, NU-601 MOF was synthesised under solvothermal conditions starting from urea 1 and 4,4'-bipyridine (bipy, 2) as a pillaring strut (Scheme 1). ${ }^{43,44}$

After 2 days of heating, light-yellow needle-shaped crystals of NU-601 MOF were obtained. The structure of $\mathrm{Zn}_{2}(\text { bipy })_{2}\left(\mathbf{1}^{-}\right.$ $4 \mathrm{H}$ ) contains $2 \mathrm{D}$ sheets of strut 1 pillared with 2 and $\mathrm{Zn}_{2}$ nodes, featuring large channels in all directions as disclosed in Fig. 2.

Since DMF molecules remained tightly hydrogen-bonded to the $\mathrm{N}-\mathrm{H}$ groups of urea in the solid, in order to activate the structure, the exchange of the DMF with $\mathrm{MeNO}_{2}$ was carried out over 4 days. After this exchange/activation process, the effectiveness of NU-601 as a hydrogen-bond donor catalyst was explored in the Friedel-Crafts alkylation between nitroalkenes and pyrroles. ${ }^{45}$

In the screening of the reaction, a higher reactivity was observed when using NU-601 as the catalyst compared with the reactivity of diphenylurea ( $90 \%$ conv. at $18 \mathrm{~h} v$ s. $65 \%$ conv.) and the control reaction ( $21 \%$ conv. at $48 \mathrm{~h}$ ). Then, in order to demonstrate if the catalysis took place on the surface of the MOF or within the pores, the authors employed larger substrates as steric probes (Scheme 2).

For this aim, pyrrole $\mathbf{3 b}$ and nitroalkene $\mathbf{4 b}$ were also employed, and a rapid decrease in the reaction rate was detected. These results provided strong evidence that NU-601

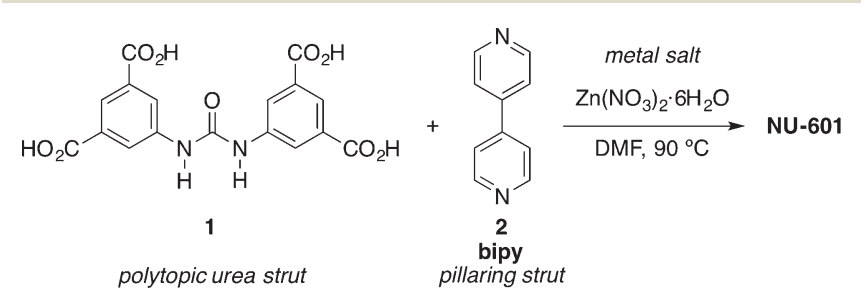

Scheme 1 Synthesis of MOF NU-601. ${ }^{43}$

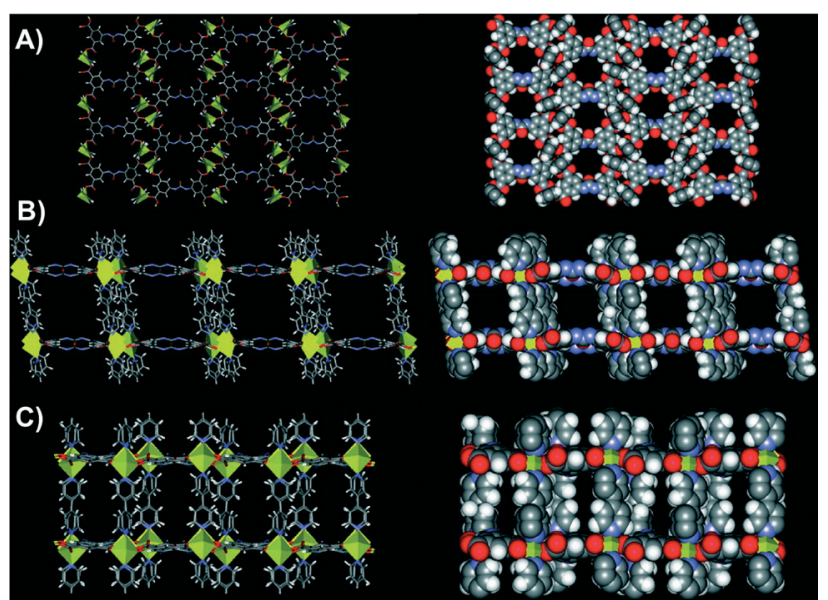

Fig. 2 Stick and space-filling representations of NU-601 $\left(P 2_{1} / c\right.$ space group). A) View down the $a$ axis (pore size $12.05 \AA \times 13.95 \AA$ ). B) View down the $b$ axis (pore size $11.38 \AA \times 13.69 \AA$ ). . C) View down the $c$ axis (pore size $11.38 \AA \times 4.87 \AA$ ). Adapted with permission from ref. 43. Copyright ${ }^{\circledR}$ American Chemical Society. 

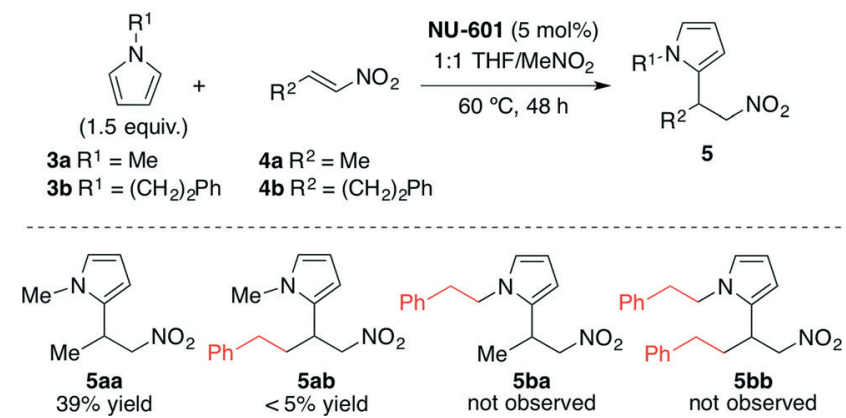

Scheme 2 Size-exclusion catalysis experiments. ${ }^{43}$

exhibited reagent size selectivity since the large substrates show significantly diminished yields because they cannot get into the porous network. NU-601 also proved to be reusable, maintaining its reactivity after one cycle of use (33\% vs. $39 \%$ yield after $48 \mathrm{~h}$ of reaction) and suffering only a slight degradation of reactivity after five cycles $(29 \%$ vs. $39 \%$ yield after $48 \mathrm{~h}$ of reaction).

The same research group reported in 2013, as an extension of their research work, ${ }^{46}$ a new class of urea-based UiO67 derivatives as plausible catalysts. ${ }^{47}$ UiO-67 is formed by a cubic metal-organic framework of cationic $\mathrm{Zr}_{6} \mathrm{O}_{4}(\mathrm{OH})_{4}$ nodes and biphenyl-4,4'-dicarboxylate (bpdc) 7 linkers, providing two pore sizes with diameters of 23 and $12 \AA$ (Fig. 3 ). ${ }^{48}$

In this study, the authors incorporated for the first time the urea scaffold into the UiO-67 MOF with the aim of designing plausible hydrogen-bond donating catalysts. In order to evaluate the effect of the porosity on the catalytic activity of the materials, different species were prepared by means of various $\mathbf{H}_{2}$-urea/ $\mathbf{H}_{2}$-bpdc ratios during the solvothermal synthesis (Scheme 3).

All prepared species were explored in the nitroaldol $(\text { Henry })^{49}$ reaction between nitromethane (9) and

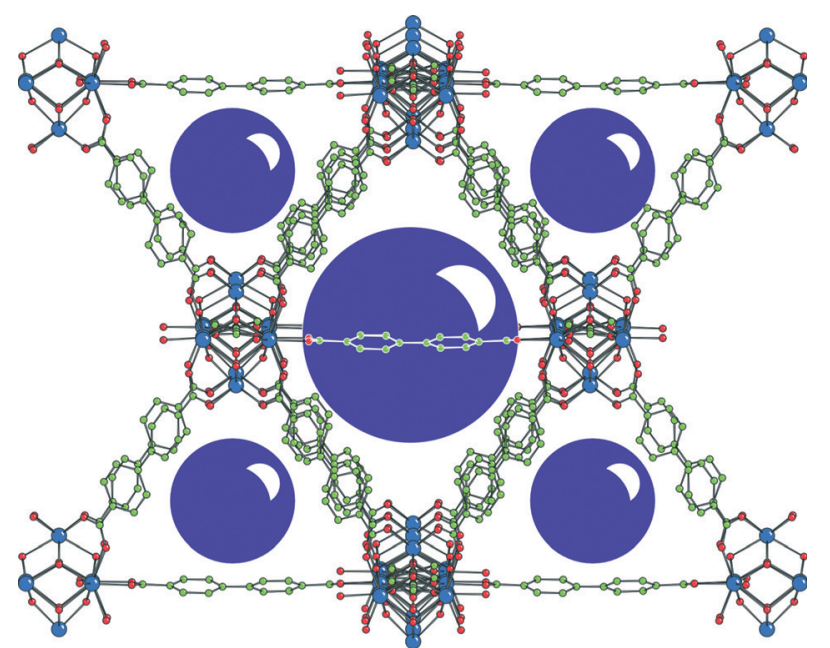

Fig. 3 UiO-67 structure represented by a single octahedral cage (large sphere). The face of each octahedral cage is shared with eight smaller tetrahedral cages (small spheres). Reprinted with permission from ref. 46. Copyright ${ }^{\circledR}$ Royal Society of Chemistry.

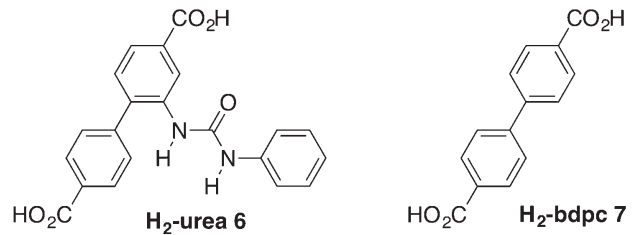

$m \mathrm{H}_{2}$-urea $6+n \mathbf{H}_{2}$-bpdc $7 \underset{\substack{\text { conc. } \mathrm{HCl} \\ \mathrm{DMF}, 80^{\circ} \mathrm{C}}}{\stackrel{\mathrm{ZrCl}_{4}}{\longrightarrow}} \mathrm{Zr}_{6} \mathrm{O}_{4}(\mathrm{OH})_{4}(\text { urea })_{x}(\text { bpdc })_{y}$

\begin{tabular}{l|llll} 
& $m$ & $n$ & $x$ & $y$ \\
\hline UiO-67 & 0 & 1 & 0 & 4 \\
UiO-67-urea & 1 & 0 & 4 & 0 \\
UiO-67-urea/bpdc & 0.5 & 0.5 & 1.44 & 2.56
\end{tabular}

Scheme 3 Synthesis of derivatives of MOF UiO- $67 .{ }^{47}$

benzaldehyde (8a) as the model reaction. The results are disclosed in Scheme 4.

The mixed strut UiO-67-urea/bpdc framework was found to be the most active catalyst (67\% yield after $24 \mathrm{~h}$ ). The results were very similar in the control experiment and when using $\mathrm{Zr}_{6} \mathrm{O}_{4}(\mathrm{OH})_{4}$ by itself (UiO-67) (14\% and $11 \%$, respectively). Interestingly, the use of UiO-67-urea afforded the same poor results (19\% yield). The best catalytic activity showed by UiO67-urea/bpdc was attributed to its high Brunauer-EmmettTeller (BET) surface area $\left(1550 \mathrm{~m}^{2} \mathrm{~g}^{-1}\right)$ compared with that of UiO-67-urea $\left(390 \mathrm{~m}^{2} \mathrm{~g}^{-1}\right)$ as measured by the authors. It is remarkable that the pore size distribution on UiO-67-urea/bpdc did not suffer a significant decrease in the pore diameters (21.5 and $12 \AA$ ) in comparison to the precursor UiO-67 (23 and $11.5 \AA$ ). In contrast, both structures are significantly larger than that of the pure strut UiO-67-urea (12 and $9 \AA$ ).

More recently, $\mathrm{Hu}$, Liu and co-workers have developed novel functionally diverse urea-derived MOF hydrogen-bonddonating heterogeneous catalysts for their application in Friedel-Crafts alkylation reactions. ${ }^{50}$ The heterogeneous catalysts were synthesised following a post-synthetic modification (PSM) approach, which has been proven to be an effective tool to introduce functional groups in MOFs. ${ }^{36,51,52}$ Thus, three different urea-containing Cr-MIL-101 (chromium(III) terephthalate MOF) heterogeneous catalysts were prepared. Cr-MIL-101- $\mathbf{N H}_{2}$ was first prepared starting from Cr-MIL-101, and then the former was submitted to react with the appropriate isocyanate in $\mathrm{CH}_{3} \mathrm{CN}$ at $120{ }^{\circ} \mathrm{C}$ in a sealed tube for $12 \mathrm{~h}$. It is noteworthy that both aliphatic and aromatic isocyanates were successfully anchored onto the MIL-101 walls via covalent incorporation, leading to Cr-MIL-101-UR1-3 in nearly

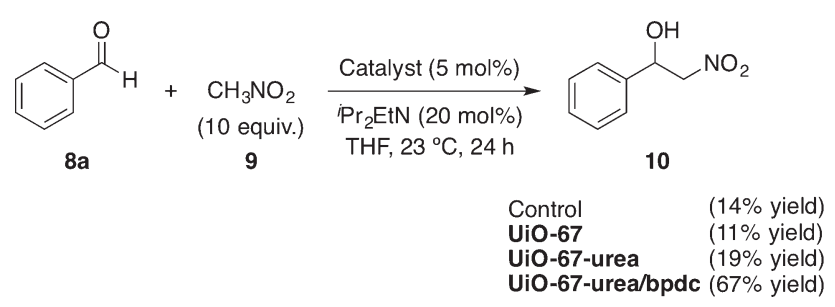

Scheme 4 Screening of the nitroaldol (Henry) reaction. ${ }^{47}$ 
quantitative conversion and catalyst loading of 2.61, 2.48 and $1.85 \mathrm{mmol} \mathrm{g}^{-1}$, respectively (Fig. 4). ${ }^{50}$ The gas sorption behavior of these MOFs demonstrated that they were still highly porous after post-synthetic modification (i.e., BrunauerEmmett-Teller (BET) surface areas were $1409.9 \mathrm{~m}^{2} \mathrm{~g}^{-1}$, $1178.6 \mathrm{~m}^{2} \mathrm{~g}^{-1}$ and $829.3 \mathrm{~m}^{2} \mathrm{~g}^{-1}$, respectively).

The catalytic activity of Cr-MIL-101-UR1-3 in the FriedelCrafts alkylation reaction was tested in the model reaction between $N$-methylpyrrole (3a) and trans- $\beta$-nitrostyrene (4c) (Table 1). ${ }^{45,50}$

After exploring different reaction conditions and catalysts, the best results were achieved with Cr-MIL-101-UR3 (entries 4 and 5), which bears appropriate steric hindered and electronwithdrawing substituents. The catalyst loading could be reduced to $10 \mathrm{~mol} \%$, without a strong influence on the yield (entry 6) and better reactivity was found in comparison with urea 11, a homogeneous catalyst (95\% vs. $79 \%$ yield, entries 5 and 12, respectively). The other two catalysts (Cr-MIL-101UR1 and Cr-MIL-101-UR2) gave poorer results than Cr-MIL101-UR3 (entries 8 and 9 compared with entry 5). The better reactivity found in the case of the latter is attributable to the spatial isolation achievable in the porous MOF environment. With the optimized conditions in hand, other electron-rich nucleophiles $(\mathbf{1 2 a}-\mathbf{c})$ and a broad scope of different

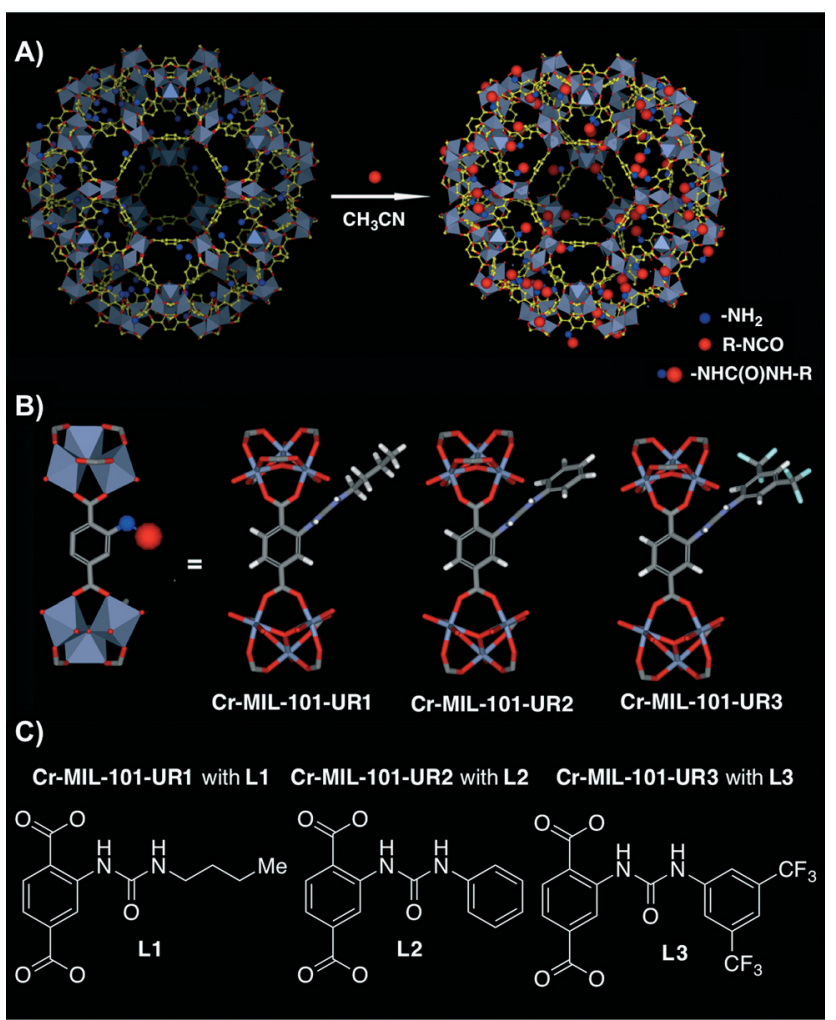

Fig. 4 A) PSM approach of $\mathrm{Cr}-\mathrm{MIL}-101-\mathrm{NH}_{2}$ with isocyanates to generate $\mathrm{Cr}$-MIL-101-UR1-3. B) Schematic representation of the ligand structure and $\left[\mathrm{Cr}_{3} \mathrm{O}\left(\mathrm{CO}_{2}\right)_{6}\right]$ cluster nodes. C) Differently substituted ureas present in the final synthesised MOFs. Adapted with permission from ref. 50. Copyright ${ }^{\circledR}$ Royal Society of Chemistry.
Table 1 Screening of the Friedel-Crafts alkylation reaction ${ }^{a, 50}$

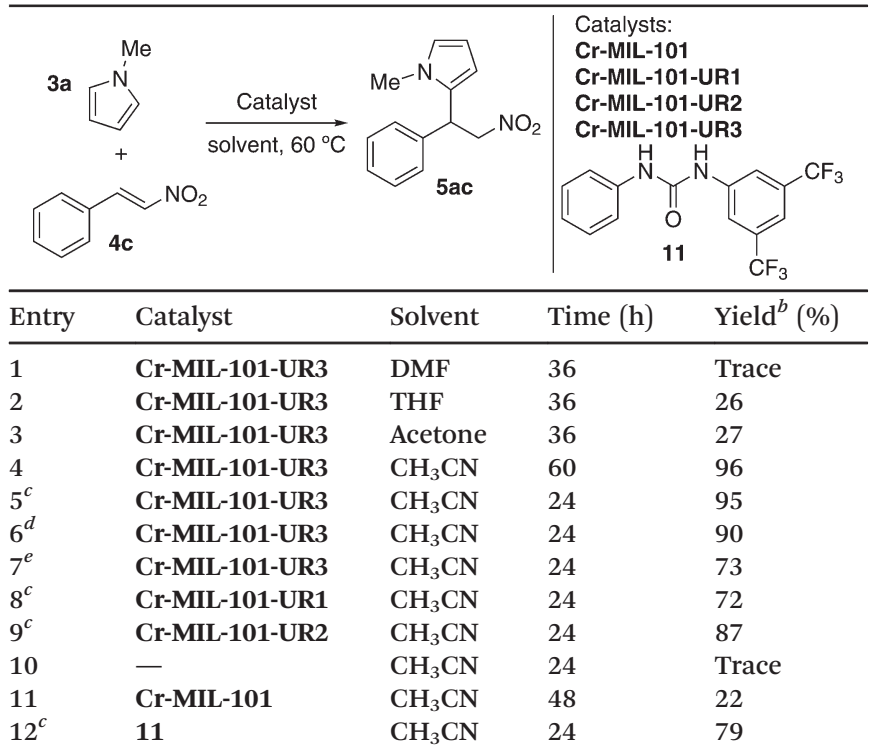

${ }^{a}$ Reactions performed with $3 \mathrm{a}(0.2 \mathrm{mmol}), 4 \mathrm{c}(0.1 \mathrm{mmol})$, and catalyst $(15 \mathrm{~mol} \%)$ in the solvent $(0.15 \mathrm{~mL}) .{ }^{b}$ Determined using ${ }^{1} \mathrm{H}$ NMR. ${ }^{c}$ Ratio $5: 1$ for $3 \mathrm{a}: 4 \mathrm{c}$ used. ${ }^{d} 10 \mathrm{~mol} \%$ catalyst loading. ${ }^{e} 5 \mathrm{~mol} \%$ catalyst loading.

nitroalkenes (4c-m) were explored, achieving the same good reactivity (Table 2).

Interestingly, with long-chain or large nitroalkenes as substrates (4l-m), better results were obtained using urea 11 (entries 12 and 13). This fact supports that the heterogeneous catalysis mainly occurred within the pores of the MOF, thus exhibiting reagent size selectivity. Moreover, the study of the recyclability of Cr-MIL-101-UR3 provided that the catalyst was easily isolated from the reaction suspension by centrifugation and reused at least four times with little loss of reactivity while retaining its crystallinity as confirmed by PXRD analysis.

Recently, Morsali and co-workers have developed another example of MOFs containing urea units inside the struts of the MOF. ${ }^{53}$ Two different MOFs (TMU-18 and TMU-19) were synthesised by reacting $\mathrm{Zn}\left(\mathrm{NO}_{3}\right)_{2} \cdot 6 \mathrm{H}_{2} \mathrm{O}$, the urea-based ligand $\left(\mathrm{H}_{2}\right.$-urea) 14 and either bipy (2) or 1,2-bis(4-pyridyl)ethane (bpe, 15) as pillaring struts under solvothermal conditions (Scheme 5). These MOFs are modified versions of the ureacontaining MOF synthesised by Farha, Hupp, Scheidt and co-workers in 2012 (ref. 43) and exhibited different characteristics. Both MOFs showed large channels along the $b c$-plane with an aperture size of $13.5 \times 9.9 \AA$ for TMU-18, and along the $b$-axis with an aperture size of $12.1 \times 10.6 \AA$ for TMU-19.

These urea-based MOFs, especially TMU-18, showed good catalytic activity in the regioselective methanolysis of diverse epoxides (Fig. 5 and Table 3). In the case of styrene oxide (16a) both catalysts provided very high conversions after $140 \mathrm{~h}(100 \%$ and $95 \%$, entry 3$)$. However, for the other three less reactive epoxides (16b-d) poorer conversions were obtained in general, even in the presence of double the 
Table 2 Screening of the Friedel-Crafts alkylation reaction ${ }^{a, 50}$

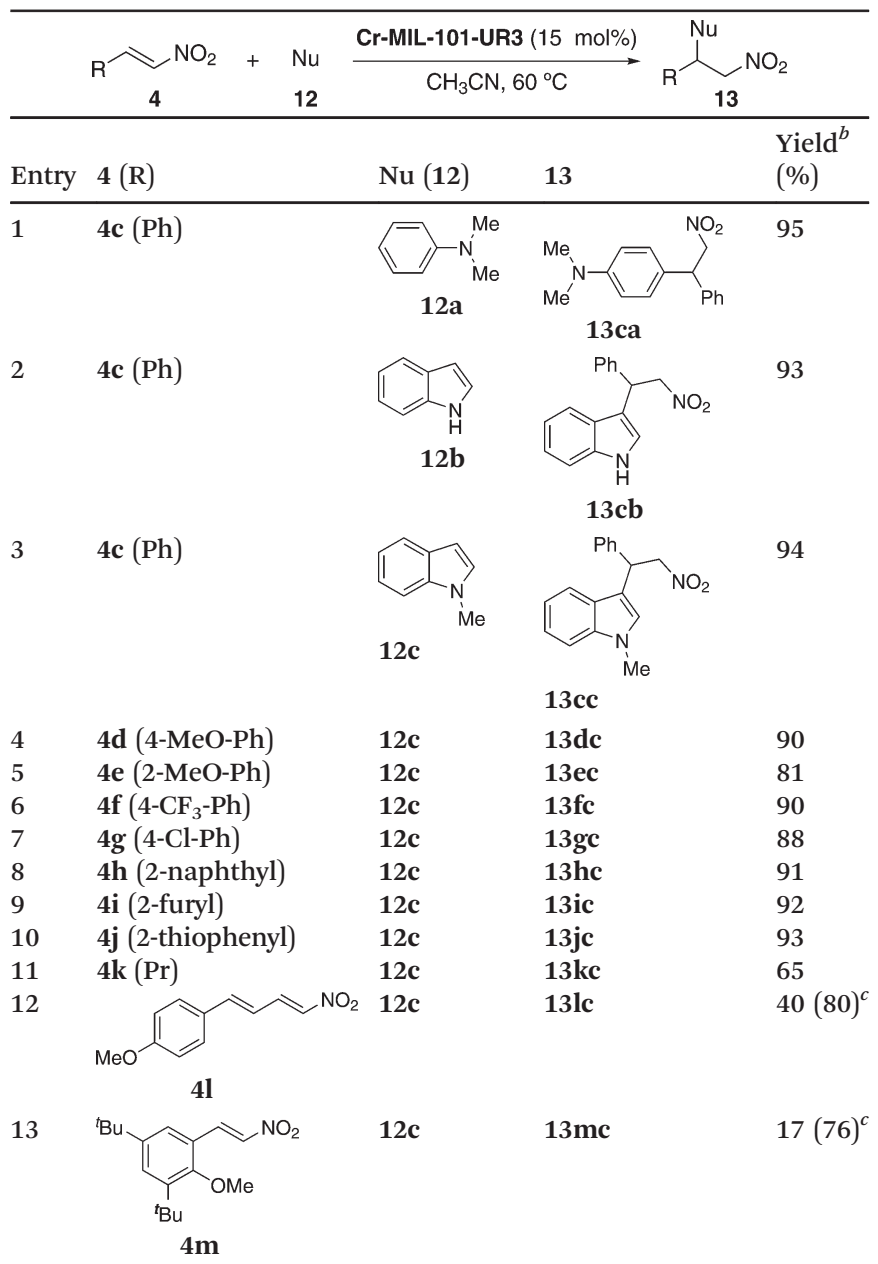

${ }^{a}$ Reactions performed with $4(0.1 \mathrm{mmol}), 12(0.12 \mathrm{mmol})$, and catalyst $(15 \mathrm{~mol} \%)$ in $\mathrm{CH}_{3} \mathrm{CN}(0.15 \mathrm{~mL}) .{ }^{b}$ Isolated yield. ${ }^{c}$ Isolated yield using catalyst 11.

amount of catalyst (50 mol\% vs. $25 \mathrm{~mol} \%$ ). In all cases, very low conversions were obtained after the same reaction time when no catalyst was used (entries 1, 5, 7 and 9 vs. 2, 6, 8 and 10, respectively). A fifth bulky epoxide (16e) was tested in order to support the happening of the reaction within the pores of the frameworks, and the low conversion reached after $140 \mathrm{~h}$ indicates it so (entry 11).

It is noteworthy to mention that the reaction conversion was lower when $40 \mathrm{~mol} \%$ of urea powder was used as catalyst (15\% vs. $35 \%$ and 31\%, with TMU-18 and TMU-19, respectively, after $24 \mathrm{~h}$ ), which proves the importance of including the urea moieties within the MOF structures. In addition, both catalysts were recovered, washed and used one more time, but they showed a decrease in their catalytic activity (39\% vs. $45 \%$ and $29 \%$ vs. $41 \%$ for TMU-18 and TMU-19, respectively, after $40 \mathrm{~h}$ ), in agreement with a gradual loss of crystallinity through the cycles as verified by PXRD measurements. However, these results open new possibilities for designing reusable urea-containing MOF catalysts for reactions
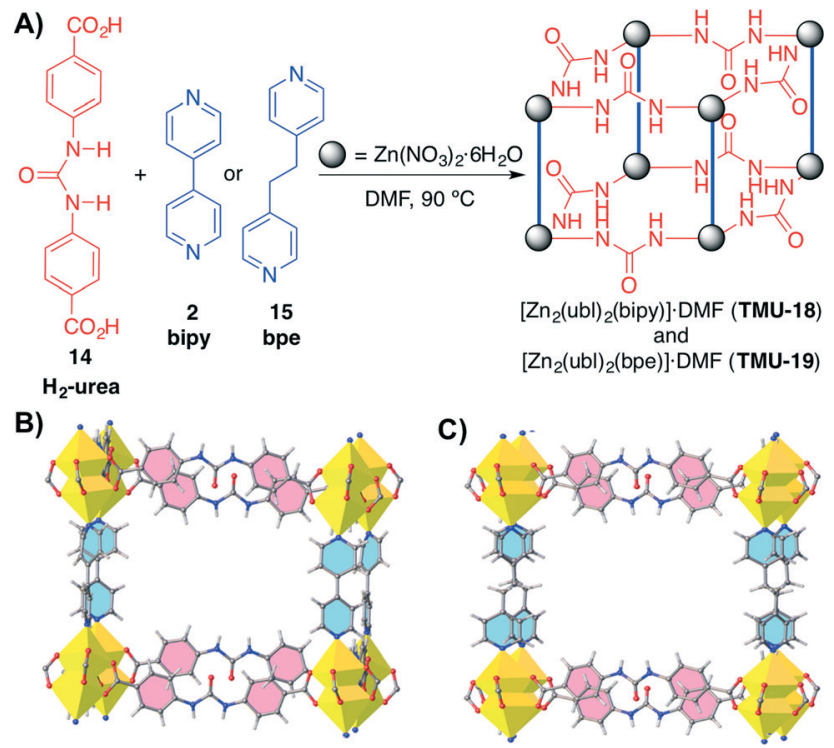

Scheme 5 A) Synthesis of catalytic urea-containing MOFs TMU-18 (triclinic $P \overline{1}$ ) and TMU-19 (orthorhombic Pnna). B) and C) View along the pore direction of TMU-18 and TMU-19, respectively. In contrast to TMU18, TGA analysis indicated a lower thermal stability for TMU-19. Adapted with permission from ref. 53 . Copyright ${ }^{\circledR}$ Royal Society of Chemistry.

carried out in aggressive media for the metal centers of the MOFs such as $\mathrm{MeOH}$.

Contemporaneously, Wang, Zhao and co-workers, along with their research line, ${ }^{54}$ designed a novel $(3,24)$-connected $r h t$-type metal organic framework (MOF Cu-UBTA). It was prepared by a solvothermal reaction between an unsymmetrical hexacarboxylate ligand $\mathrm{H}_{6}-\mathrm{L}$ (18) containing a urea group and $\mathrm{Cu}\left(\mathrm{NO}_{3}\right)_{2}$ in DMF at $75^{\circ} \mathrm{C}$ for 3 days (Fig. 6). ${ }^{55}$

As a proof of its high porosity, the application of Cu-UBTA in gas storage and separation was further evaluated towards $\mathrm{CO}_{2}, \mathrm{H}_{2}$ and $\mathrm{N}_{2}$. The results disclosed in Fig. 7 suggested a high selectivity with $\mathrm{CO}_{2}$ and $\mathrm{H}_{2}$ against $\mathrm{N}_{2}$.

The catalytic activity of Cu-UBTA was also evaluated using the Friedel-Crafts alkylation reaction between $N$-methylpyrrole (3a) and trans- $\beta$-nitrostyrene (4c) as a model reaction (Scheme 6).

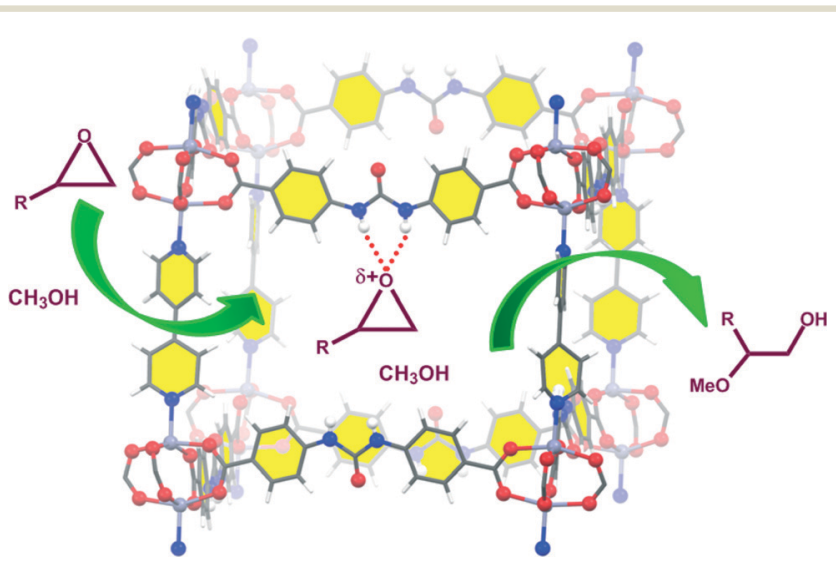

Fig. 5 Activation of epoxides by TMU-18 for their regioselective methanolysis. Reprinted with permission from ref. 53. Copyright ${ }^{\circledR}$ Royal Society of Chemistry. 
Table 3 Catalytic activities of TMU-18 and TMU-19 in the methanolysis of epoxides $16 \mathrm{a}-\mathrm{e}^{a, 53}$

\begin{tabular}{|c|c|c|c|c|c|}
\hline & & $\frac{\mathrm{TMU}-18 \text { or TI }}{\mathrm{MeOH}, 60^{\circ} \mathrm{C}}$ & $\stackrel{\vec{U}-19}{\longrightarrow} R^{\prime}$ & $\mathrm{CH}$ & \\
\hline Entry & Substrate & Major product & $\begin{array}{l}\text { Catalyst } \\
\text { loading } \\
(\mathrm{mol} \%)\end{array}$ & $\begin{array}{l}\text { Conv. }^{b, c} \\
(\%) \\
\text { TMU-18 }\end{array}$ & $\begin{array}{l}\text { Conv. }^{b, c} \\
(\%) \\
\text { TMU-19 }\end{array}$ \\
\hline 1 & 16a & 17a & - & 19 & \\
\hline 2 & $16 a$ & $17 a$ & 25 & $78(96)$ & $72(97)$ \\
\hline $3^{d}$ & $16 a$ & $17 a$ & 25 & $100(98)$ & $95(98)$ \\
\hline 4 & $16 a$ & $17 a$ & 50 & $100(98)$ & $95(98)$ \\
\hline 5 & $16 b$ & $17 \mathrm{~b}$ & - & 22 & \\
\hline $\begin{array}{l}6 \\
7\end{array}$ & $\begin{array}{l}16 b \\
16 c\end{array}$ & $\begin{array}{l}17 b \\
17 c\end{array}$ & $\begin{array}{l}50 \\
-\end{array}$ & $\begin{array}{l}78(96) \\
26\end{array}$ & $67(91)$ \\
\hline 8 & $16 \mathrm{c}$ & $\mathrm{O}^{\mathrm{Me}} \mathrm{Or}$ & 50 & $64(81)$ & $53(77)$ \\
\hline 9 & 16d & $17 \mathrm{~d}$ & - & 16 & \\
\hline $\begin{array}{l}10 \\
11^{d}\end{array}$ & 16d & 17d & $\begin{array}{l}50 \\
25\end{array}$ & $\begin{array}{l}51(78) \\
9\end{array}$ & $\begin{array}{l}48(72) \\
6\end{array}$ \\
\hline
\end{tabular}

${ }^{a}$ Reactions performed with $16 \mathrm{a}-\mathrm{e}(0.2 \mathrm{mmol})$ and the appropriate amount of urea catalyst in methanol $(3 \mathrm{~mL})$ at $60{ }^{\circ} \mathrm{C}$. ${ }^{b} \mathrm{GC}$ yield using the internal-standard method. ${ }^{c}$ The data in parentheses correspond to the selectivity for the major product. ${ }^{d} 140 \mathrm{~h}$ reaction time.

With Cu-UBTA the desired product was obtained in $85 \%$ yield after $48 \mathrm{~h}$, whereas only traces of the product were observed in the control experiment without catalyst. In order to confirm the utility of the urea moiety in the catalytic system, the authors used their previous MOF NTU-105 (ref. 54) without urea as the catalyst under the same reaction conditions. Interestingly, NTU-105 exhibited a lower catalytic activity in relation to Cu-UBTA. This fact confirmed that the urea group in rht-MOF Cu-UBTA could also function as a hydrogen-bonddonating site to catalyse the Friedel-Crafts reaction in a synergic effect with the open metal sites, since the moderate catalytic activity shown by NTU-105 was attributed to the Lewis acidic open copper sites in the structure. The scope of the application of this catalyst was extended to other nucleophiles (12c) and nitroalkenes 4, leading to the desired products with good to excellent yields (Table 4). The recyclability of the MOF was also explored and the catalyst was reused after a simple centrifugation, showing similar catalytic activity in successive reaction cycles $(81 \%$ for the 2 nd run, $75 \%$ for the 3rd run). Moreover, PXRD measurements of the recycled catalyst revealed that the MOF retained its crystallinity after the catalytic cycles.
A)

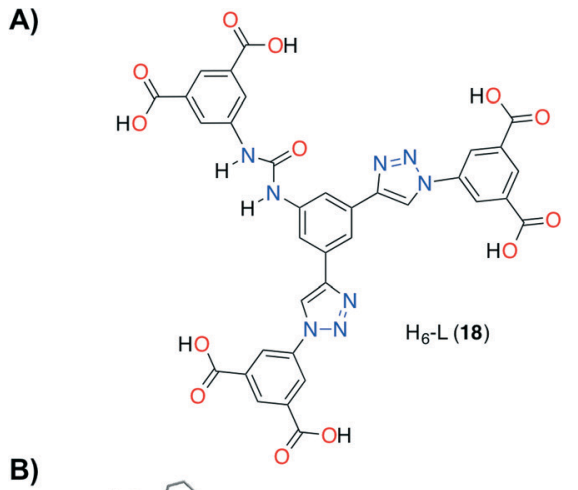

B)

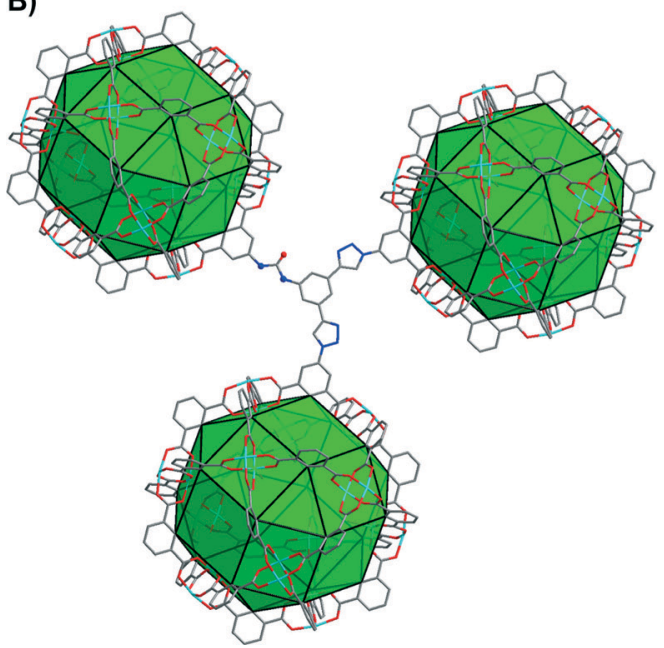

Fig. 6 A) Structure of the hexacarboxylate acid $\mathrm{H}_{6}-\mathrm{L}$ (18). B) Single crystal structure of the $(3,24)$-connected rht-topological framework in Cu-UBTA. Tetragonal space group $14 / \mathrm{m}$, unit cell dimensions $a=b=$ $31.4206 \AA$ A $c=44.8239 \AA$ A. BET surface area $=3134 \mathrm{~m}^{2} \mathrm{~g}^{-1}$. Adapted with permission from ref. 55 . Copyright $®$ Royal Society of Chemistry.

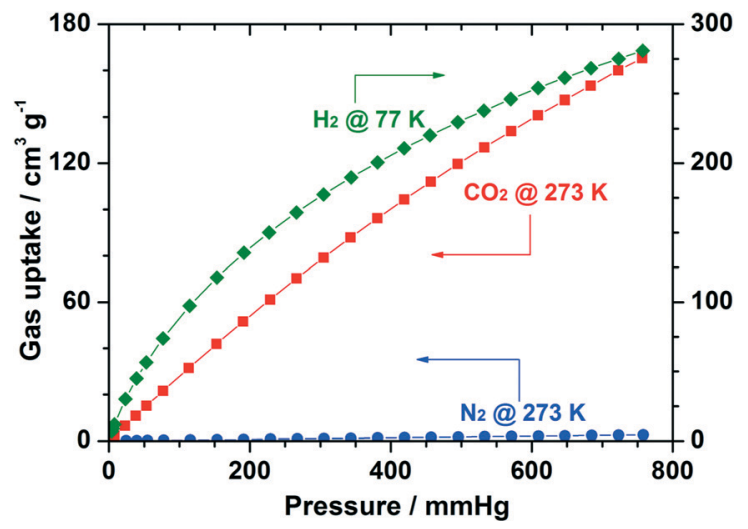

Fig. 7 Gas sorption isotherms of Cu-UBTA for $\mathrm{CO}_{2}$ and $\mathrm{N}_{2}$ (at $273 \mathrm{~K}$ ), and $\mathrm{H}_{2}$ (at $77 \mathrm{~K}$ ). Reprinted with permission from ref. 55. Copyright ${ }^{\circledR}$ Royal Society of Chemistry.

\section{Thiourea-containing MOF catalysts}

With the idea in mind of preventing also the self-quenching and to make possible the recycling of thiourea catalysts, Wang and co-workers have recently immobilised thiourea 

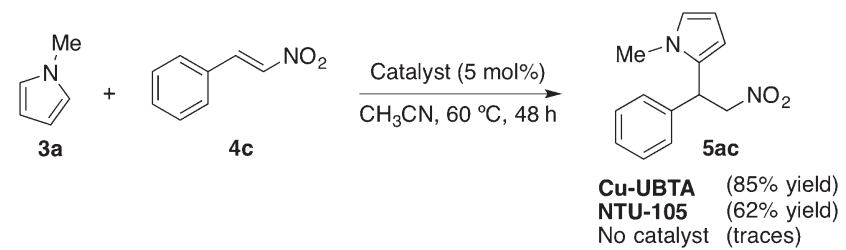

Scheme 6 Model Friedel-Crafts alkylation reaction catalysed by CU-UBTA. ${ }^{55}$

Table 4 Scope of the Friedel-Crafts reaction ${ }^{a, 55}$

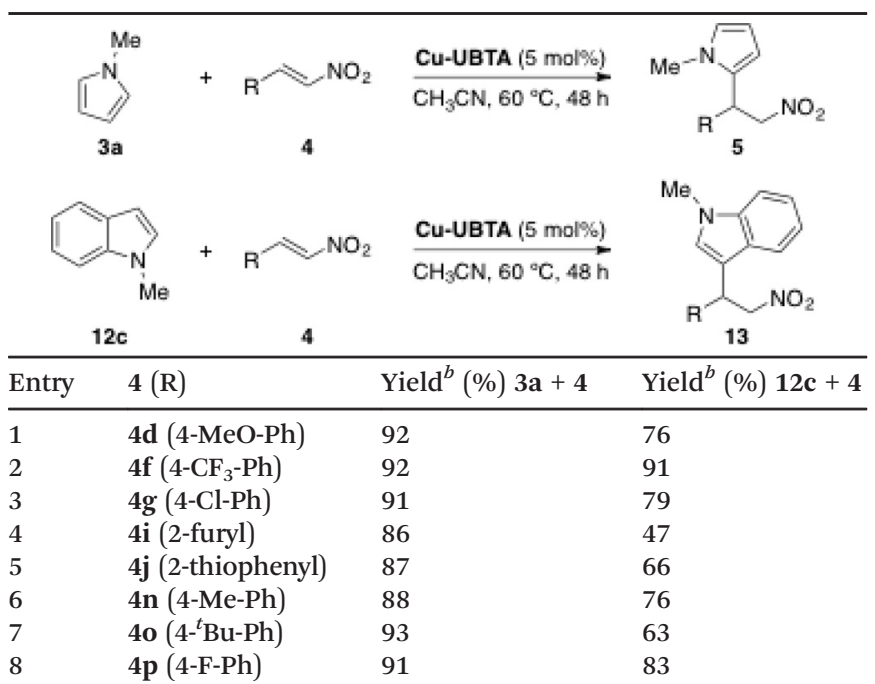

${ }^{a}$ Reactions were carried out with $3 \mathrm{a}$ or $12 \mathrm{c}(0.2 \mathrm{mmol}), 4(0.1 \mathrm{mmol})$ and catalyst Cu-UBTA ( 5 mol\%) in $\mathrm{CH}_{3} \mathrm{CN} .{ }^{b}$ Determined by ${ }^{1} \mathrm{H}$ NMR using the internal-standard method.

functionalities into IRMOF-3 following a post-synthetic modification strategy (PSM) ${ }^{56}$ The synthesis was addressed with IRMOF-3, a porous MOF with primary amine groups in its structure, which was further modified by adding an isothiocyanate under basic conditions (Scheme 7).

The introduction of the thiourea functionalities did not affect the nanomorphology of IRMOF-3 as shown in Fig. 8, since similar cubic crystals were produced in both cases. This indicates the high similarity of both crystalline structures. In addition, the obtained nano MOF catalyst showed good thermal stability (up to $\sim 344{ }^{\circ} \mathrm{C}$ ) similar to IRMOF-3.

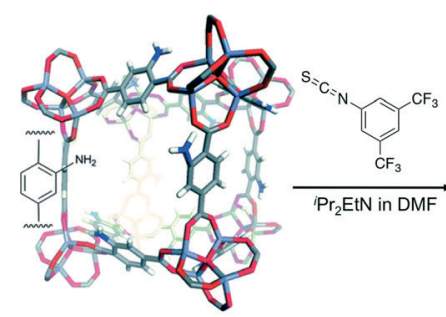

IRMOF-3

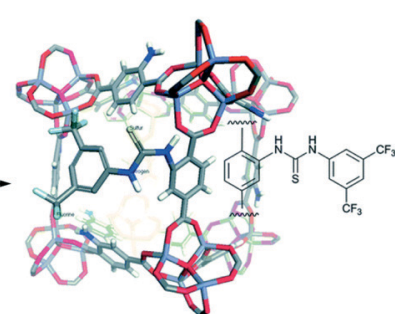

IRMOF-3-thiourea-3,5-( $\left(\mathrm{CF}_{3}\right)_{2} \mathrm{Ph}$
Scheme 7 PSM approach between IRMOF-3 with 3,5bis(trifluoromethyl)phenyl isothiocyanate. Adapted with permission from ref. 56 . Copyright ${ }^{\circledR}$ Royal Society of Chemistry.

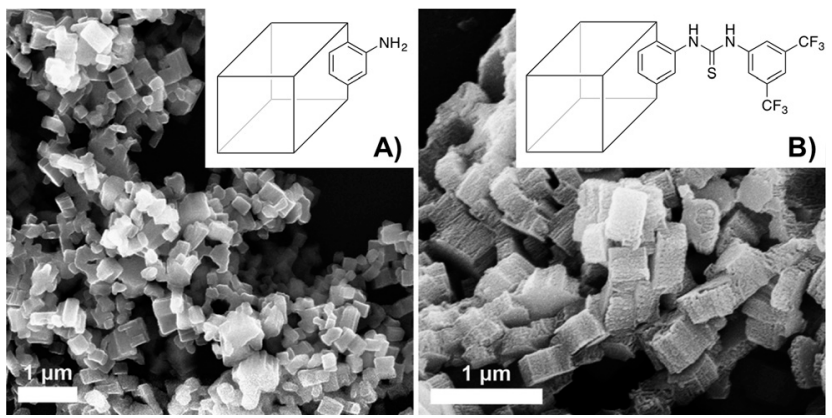

Fig. 8 SEM images of nanoscale A) IRMOF-3 and B) IRMOF-3thiourea-3,5-(CF $)_{2} \mathrm{Ph}$ derivative. Reprinted with permission from ref. 56. Copyright ${ }^{\circledR}$ Royal Society of Chemistry.

An initial screening of the acetalisation reaction of benzaldehyde (8a) at room temperature was performed testing all the catalysts synthesised (Table 5).

As shown in Table 5, IRMOF-3 did not work after $12 \mathrm{~h}$ (entry 5) and this is in agreement with the fact that the thiourea moiety seems to be responsible for the acetalisation reactivity. ${ }^{57}$ The phenyl-substituted IRMOF-3-thiourea-Ph catalyst

Table 5 Screening of the acetalisation reaction ${ }^{a, 56}$
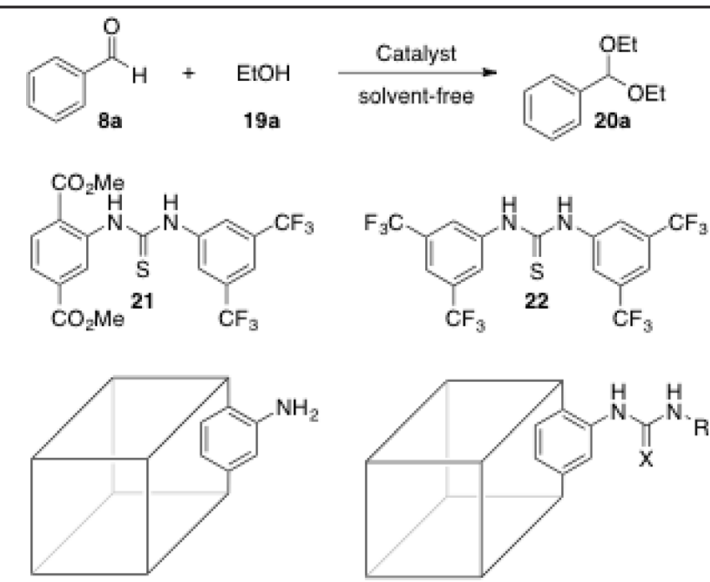

IRMOF-3 $\begin{array}{ll}\text { IRMOF-3-thiourea-Ph } & X=S, R=P h \\ \text { IRMOF-3-thiourea-3,5-(CF })_{2} P h & X=S, R=3,5-C_{3}-P h \\ \text { IRMOF-3-urea-3,5-(CF })_{2} P h & X=O, R=3,5-C F_{3}-P h\end{array}$

\begin{tabular}{|c|c|c|c|}
\hline try Catalyst ${ }^{b}$ & $\begin{array}{l}\text { Loading } \\
\text { (mol\%) }\end{array}$ & $\begin{array}{l}\text { Yield }^{c} \\
(\%)\end{array}$ & TON \\
\hline - & - & 0 & 0 \\
\hline$p$-TsOH & 10 & 99 & 10 \\
\hline Thiourea 21 & 1 & 81 & 81 \\
\hline Thiourea 22 & 1 & 89 & 89 \\
\hline IRMOF-3 & 10 & 6 & 0.6 \\
\hline IRMOF-3-thiourea-Ph & 0.2 & 15 & 75 \\
\hline IRMOF-3-urea-3,5-( $\left(\mathrm{CF}_{3}\right)_{2} \mathrm{Ph}$ & 0.2 & 64 & 320 \\
\hline IRMOF-3-thiourea-3,5-( $\left(\mathrm{CF}_{3}\right)_{2} \mathbf{P h}^{d}$ & 0.2 & 96 & 480 \\
\hline Bulk (IRMOF-3-thiourea-3,5-( $\left.\mathbf{C F}_{3}\right)_{2} \mathbf{P h}^{d}$ ) & 0.2 & 82 & 410 \\
\hline IRMOF-3-thiourea-3,5-( $\left(\mathrm{CF}_{3}\right)_{2} \mathbf{P h}^{e}$ & 0.2 & 98 & 490 \\
\hline
\end{tabular}

${ }^{a}$ The reaction was performed using benzaldehyde $(8 \mathrm{a})(1.0 \mathrm{mmol})$, dry ethanol (19a) $(4.0 \mathrm{mmol})$ and the appropriate amount of the organocatalyst at room temperature for $12 \mathrm{~h} .{ }^{b} \mathrm{MOF}$ catalysts are used in nanoscale unless otherwise noted. ${ }^{c}$ Determined by GC-MS. ${ }^{d} 17 \%$ thiourea incorporation. ${ }^{e} 26 \%$ thiourea incorporation. 
exhibited low reactivity (entry 6) in comparison to the 3,5bis(trifluoromethyl)-phenylthiourea derivative IRMOF-3-thiourea-3,5-( $\left(\mathbf{C F}_{3}\right)_{2} \mathbf{P h}$ (entry 8). The latter afforded higher reactivity than its urea counterpart (entry 7) and also showed better activity than its bulk partner (regular MOF instead of nano MOF) (entry 9), which suggested a higher utilization rate of the MOF surface and pore. A higher thiourea loading (26\% vs. $17 \%$ thiourea incorporation) on the catalyst led to a comparable yield (98\% vs. 96\%, respectively), with turnover numbers (TON) of up to 490 (vs. 480) (entry 10). With the best reaction conditions in hand, IRMOF-3-thiourea-3,5-( $\left(\mathbf{C F}_{3}\right)_{2} \mathbf{P h}$ (with $26 \%$ thiourea incorporation) was applied successfully to a range of substrates for acetalisation and Morita-Baylis-Hillman reactions (Table 6).

Table 6 Scope for the acetalisation and Morita-Baylis-Hillman reactions ${ }^{56}$

Entry

${ }^{a}$ Reaction conditions: for acetalisation (entries 1-4): aldehyde (8a-d) (1 mmol), dry alcohol $(19 a, b)(4 \mathrm{mmol})$ and catalyst $(0.2 \mathrm{~mol} \%)$ at room temperature for $12 \mathrm{~h}$. Yields were determined by GC-MS. ${ }^{b}$ For the Morita-Baylis-Hillman reaction (entries 5 and 6): aldehyde (8a, e) (1 mmol), 2-cyclopenten-1-one (23) ( $2 \mathrm{mmol}), 1,4$-diazabicyclo[2.2.2] octane $(0.5 \mathrm{mmol})$ and catalyst $(2 \mathrm{~mol} \%)$ were stirred at $4{ }^{\circ} \mathrm{C}$ for $24 \mathrm{~h}$. The product was purified by column chromatography on silica gel and the yield was based on the isolated product.

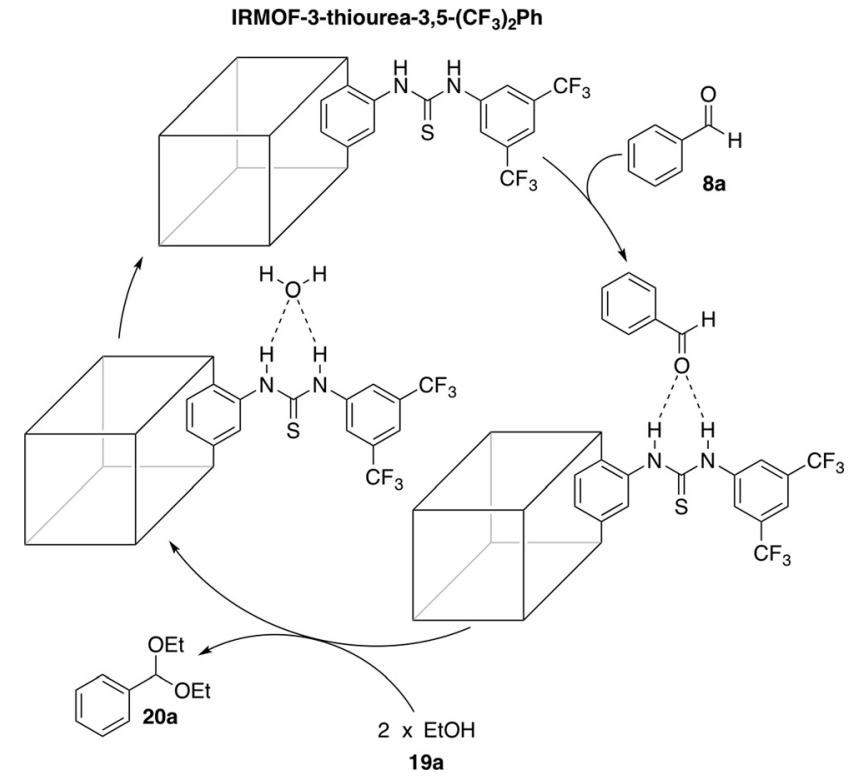

Scheme 8 Mechanistic proposal for the acetalisation reaction catalysed by IRMOF-3-thiourea-3,5-( $\left(\mathrm{CF}_{3}\right)_{2} \mathrm{Ph}^{56}$

The strong covalent bond between the thiourea moiety and the amino group on IRMOF-3 ensures the stability of the catalytic functional groups, which maintains over 95\% yield after 5 cycles. PXRD and FTIR analyses showed no differences before and after the recycling experiments. The mechanism depicted in Scheme 8 was proposed for the catalytic acetalisation of aldehydes. It starts with the coordination of the catalyst with the carbonyl group. Then, the nucleophilic attack of two alcohols through an ion-pair intermediate, which leads to benzaldehyde acetal and $\mathrm{H}_{2} \mathrm{O}$ binding, takes place. And finally, the dehydration of $\mathrm{H}_{2} \mathrm{O}$ through ligand exchange regenerates the catalyst. In the case of the $\mathrm{M}-\mathrm{B}-\mathrm{H}$ reaction the nucleophile is compound 23 in the presence of a base.

\section{Squaramide-containing MOF catalysts}

Hupp, Farha, Mirkin and co-workers have recently developed the first example of a MOF bearing acidic squaramide moieties: UiO-67-Squar/bpdc. ${ }^{58}$ In the synthesis of this material, preparation of the squaramide-functionalised strut $\left(\mathbf{H}_{2}-\right.$ Squar, 27) was first achieved from dimethyl 2-aminobiphenyl4,4'-dicarboxylate (25) and 3-((3,5-bis-(trifluoromethyl)phenyl) amino)-4-methoxycyclobut-3-ene-1,2-dione (26) (Scheme 9). Then, it was incorporated into a zirconium-cluster-based UiO-67 MOF by reaction with the biphenyl chain $\left(\mathbf{H}_{2}\right.$-bpdc, 7$)$ in the presence of $\mathrm{ZrCl}_{4}$ as the source of metal. This 1:1 molar ratio mixed-strut approach was used to accommodate the relatively sterically demanding squaramide motif and to maintain open pores.

MOF UiO-67-Squar/bpdc was employed successfully as the catalyst for the Friedel-Crafts reaction between indole (12b) and nitrostyrene (4c) (Table 7, entry 6). The introduction of 

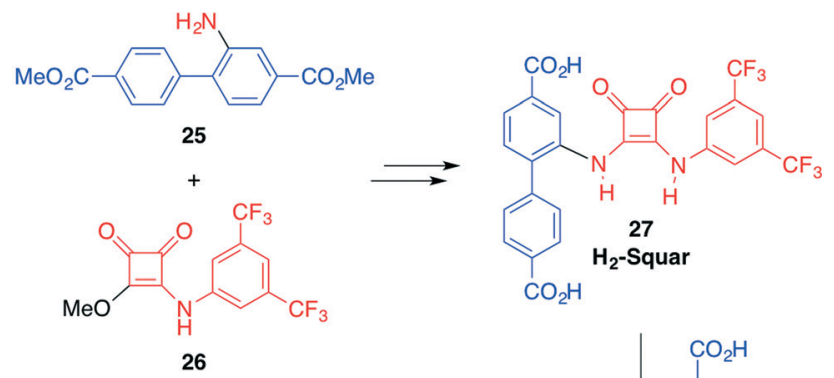

Table 7 Selected screening of the Friedel-Crafts reaction using different catalysts $^{a, 58}$

Scheme 9 Synthesis of squaramide-based MOF UiO-67-Squar/bpdc and its structure. BET surface areas: $2500 \mathrm{~m}^{2} \mathrm{~g}^{-1}$ (UiO-67), $1700 \mathrm{~m}^{2} \mathrm{~g}^{-1}$ (UiO-67-Squar/bpdc). ${ }^{58}$

\begin{tabular}{llll} 
& & \\
\hline
\end{tabular}

${ }^{a}$ Reactions performed with $3 \mathrm{c}$ or $12 \mathrm{~b}(0.03 \mathrm{M}), 4 \mathrm{c}(0.02 \mathrm{M})$ and the catalyst $(10 \mathrm{~mol} \%)$ in $\mathrm{CD}_{2} \mathrm{Cl}_{2}$ at r.t. ${ }^{b}$ Determined by ${ }^{1} \mathrm{H}$ NMR spectroscopy. ${ }^{c} 10 \mathrm{~mol} \% \mathrm{MOF}$ and $10 \mathrm{~mol} \%$ methyl ester analogous of squaramide 27 ( $\mathrm{Me}_{2}$-Squar, $\left.27^{\prime}\right){ }^{d}$ 1,2-Dichlorobenzene- $d_{4}$ was used as solvent, at $50{ }^{\circ} \mathrm{C}$. ${ }^{e}$ Toluene- $d_{8}$ was used as solvent, at $50{ }^{\circ} \mathrm{C}$.

different amounts of squaramide groups into this MOF affected to a great extent the reaction rate. When all the biphenyl groups were substituted with squaramide units (UiO-67-Squar), the reactions showed similar outcomes compared to those obtained with the control experiment using only the non-substituted MOF (UiO-67) (entries 2 and 5). This lack of catalytic activity may be due to the formation of intermolecular bonds that block reactive squaramide centers and/ or the shrinking of the pores of the MOF. However, when they employed UiO-67-Squar/bpdc with only $50 \%$ of the biphenyl groups linked to squaramide moieties, the results observed were much higher than those of the control experiment (Table 7, entry 6). The authors attributed this improvement in the reactivity to a decrease in the selfaggregation of squaramides, since any cooperative effect was observed between UiO-67 and the free squaramide ( $\mathbf{M e}_{2}$-Squar (27'), the methyl ester analogues of squaramide 27) (Table 7, entry 4). Interestingly, when using low-polarity solvents at a higher temperature $\left(50{ }^{\circ} \mathrm{C}\right)$, the corresponding product $5 \mathrm{cc}$ was obtained in nearly complete conversion (Table 7 , entries 7 and 8).

In the case of using pyrrole (3c) as the nucleophile, a lower conversion was achieved under the same conditions described for indole (compare entries 2 and 6 with 10 and 11, respectively). Remarkably, this catalyst could be reused through multiples cycles, yet a little decrease in the yield is observed over successive catalytic cycles.

\section{Summary and outlook}

In conclusion, the modular synthesis, tunable topology, large surface area and intrinsic porosity of MOFs make them very promising materials for heterogeneous catalysis. The welldefined confined space imposed by MOFs provides a unique functional microenvironment with catalytic sites uniformly arranged along the 3D supramolecular structure. The versatile field of MOF-based heterogeneous catalysis is now offering a new world of possibilities for hydrogen-bonding organocatalysts by overcoming self-aggregation and solvation issues that are usually found in homogeneous conditions. The first examples of urea-, thiourea- and squaramidecontaining MOFs have demonstrated their effectiveness in relevant chemical transformations such as Friedel-Crafts reactions, nitroaldol (Henry) reactions, acetalisation, alcoholysis of epoxides and Morita-Baylis-Hillman reactions. In general, the results derived from these studies support the conclusion that catalysis occurs mainly within the pores of the functionalised MOFs, showing improved catalyst stability and substrate size selectivity in comparison to the analogous homogeneous catalysts. Moreover, the organocatalyst-containing MOFs could be easily separated and recycled several times without loss of activity and/or major leaching problems.

These materials can be synthesised using either organocatalyst-containing organic struts or by post-synthetic modification of suitable functionalised MOFs. Obviously, the enhancement of the thermochemical stability of the hybrids as well as the achievement of larger size cavities constitute major aspects to consider when engineering new MOF-based organocatalytic systems that are expected to compete with 
other porous materials such as zeolites and mesoporous silica. However, the development of hydrogen-bonding organocatalyst-containing MOFs is still in its infancy with only the few examples summarized in this contribution. Many other examples are still necessary to demonstrate the reliability and broad use of these materials. In this sense, we anticipate intense research activities focused on asymmetric transformations via the introduction of chiral hydrogenbonding organocatalysts, ${ }^{59,60}$ cascade or tandem reactions through the engineering of multiple catalytic sites and the activation of new reactive pathways that are otherwise unfeasible. The development of a new generation of MOF materials with the ability to respond to external stimuli that are common during a given reaction would facilitate the control of the catalytic function as an autonomous on-off unit. Moreover, appropriate comparative studies in terms of overall costs, reaction times, catalyst loading and TON/TOF numbers with the current homogeneous catalysts used in industry will be necessary to establish the real impact of these new heterogeneous organocatalysts. The report of isolated yields in future works could also provide additional credibility to the potential advantages of these heterogeneous catalysts.

We are convinced that the examples and results highlighted in this contribution will serve as an inspiration for the development of superior hydrogen-bonding organocatalysts to accomplish, in confined spaces, chemical transformations that are either slow or unaffordable under homogeneous conditions.

\section{Acknowledgements}

Universität Regensburg, Deutsche Forschungsgemeinschaft (DFG, 9209720), Universidad de Zaragoza (JIUZ-2014-CIE-07), Consejo Superior de Investigaciones Científicas (CSIC, PIE201580I010) and Diputación General de Aragón (DGA) (Research Group E-104) are acknowledged for financial support. J. V. A.-R. thanks DGA for a predoctoral fellowship. D. D. D. thanks DFG for the Heisenberg Professorship Award.

\section{Notes and references}

1 J. Elemans, J. Cornelissen, M. Feiters, A. Rowman and R. Nolte, in Supramolecular Catalysis, ed. P. W. N. M. van Leeuwen, Wiley, 2008, ch. 6.

2 Z. J. Wang, K. N. Clary, R. G. Bergman, K. N. Raymond and F. D. Toste, Nat. Chem., 2013, 5, 100.

3 J. Meeuwissen and J. N. H. Reek, Nat. Chem., 2010, 2, 615.

4 P. Tundo, P. Anastas, D. S. Black, J. Breen, T. Collins, S. Memoli, J. Miyamoto, M. Polyakoff and W. Tumas, Pure Appl. Chem., 2000, 72, 1207.

5 S. R. Seidel and P. J. Stang, Acc. Chem. Res., 2002, 35, 972.

6 D. Fiedler, D. Leung, R. Bergman and K. Raymond, Acc. Chem. Res., 2005, 38, 351.

7 R. W. Saalfrank, H. Maid and A. Scheurer, Angew. Chem., Int. Ed., 2008, 47, 8794.

8 M. Yoshizawa, J. K. Klosterman and M. Fujita, Angew. Chem., Int. Ed., 2009, 48, 3418.
9 M. J. Wiester, P. A. Ulmann and C. A. Mirkin, Angew. Chem., Int. Ed., 2011, 50, 114.

10 J. J. Perry IV, J. A. Perman and M. Zaworotko, Chem. Soc. Rev., 2009, 38, 1400.

11 Z. Wang, G. Chen and K. Ding, Chem. Rev., 2009, 109, 322.

12 N. Ahmad, A. H. Chughtai, H. A. Younus and F. Verpoort, Coord. Chem. Rev., 2014, 280, 1.

13 M. O'Keeffe, Chem. Soc. Rev., 2009, 38, 1215.

14 M. O'Keeffe, M. A. Peskov, S. J. Ramsden and O. M. Yaghi, Acc. Chem. Res., 2008, 41, 1782.

15 G. Férey, Chem. Soc. Rev., 2008, 37, 191.

16 J. Y. Lee, O. K. Farha, J. Roberts, K. A. Scheidt, S. T. Nguyen and J. T. Hupp, Chem. Soc. Rev., 2009, 38, 1450.

17 E. N. Jacobsen and D. W. C. MacMillan, Proc. Natl. Acad. Sci. U. S. A., 2010, 107, 20618.

18 L. J. Murray, M. Dincă and J. R. Long, Chem. Soc. Rev., 2009, 38, 1294.

19 J.-R. Li, R. J. Kuppler and H.-C. Zhou, Chem. Soc. Rev., 2009, 38, 1477.

20 M. P. Suh, H. J. Park, T. K. Prasad and D.-W. Lim, Chem. Rev., 2011, 112, 782.

21 K. K. Tanabe and S. M. Cohen, Chem. Soc. Rev., 2011, 40, 498.

22 A. Carne, C. Carbonell, I. Imaz and D. Maspoch, Chem. Soc. Rev., 2011, 40, 291.

23 M. D. Allendorf, C. A. Bauer, R. K. Bhakta and R. J. T. Houk, Chem. Soc. Rev., 2009, 38, 1330.

24 L. E. Kreno, K. Leong, O. K. Farha, M. Allendorf, R. P. Van Duyne and J. T. Hupp, Chem. Rev., 2012, 112, 1105.

25 J. An and N. L. Rosi, J. Am. Chem. Soc., 2010, 132, 5578.

26 A. C. McKinlay, R. E. Morris, P. Horcajada, G. Férey, R. Gref, P. Couvreur and C. Serre, Angew. Chem., Int. Ed., 2010, 49, 6260 .

27 W. Morris, W. E. Briley, E. Auyeung, M. D. Cabezas and C. A. Mirkin, J. Am. Chem. Soc., 2014, 136, 7261.

28 T. Zhang and W. Lin, Chem. Soc. Rev., 2014, 43, 5982.

29 O. K. Farha, I. Eryazici, N. C. Jeong, B. G. Hauser, C. E. Wilmer, A. A. Sarjeant, R. Q. Snurr, S. T. Nguyen, A. O. Z. R. Yazaydın and J. T. Hupp, J. Am. Chem. Soc., 2012, 134, 15016.

30 H. Deng, S. Grunder, K. E. Cordova, C. Valente, H. Furukawa, M. Hmadeh, F. Gándara, A. C. Whalley, Z. Liu and S. Asahina, Science, 2012, 336, 1018.

31 H. Furukawa, K. E. Cordova, M. O'Keeffe and O. M. Yaghi, Science, 2013, 341, 123044.

32 A. H. Chughtai, N. Admad, H. A. Younus, A. Laypkov and F. Verpoort, Chem. Soc. Rev., 2015, 44, 6804.

33 C. Volkringer and S. M. Cohen, Angew. Chem., Int. Ed., 2010, 49, 4644.

34 T. Lescouet, J. G. Vitillo, S. Bordiga, J. Canivet and D. Farrusseng, Dalton Trans., 2013, 42, 8249.

35 A. Dhakshinamoorthy, M. Alvaro and H. Garcia, Chem. Commun., 2012, 48, 11275.

36 S. M. Cohen, Chem. Rev., 2012, 112, 970.

37 For recent excellent reviews on MOF heterogeneous catalysts, see ref. 16 and L. Ma, C. Abney and W. Lin, Chem. 
Soc. Rev., 2009, 38, 1248; M. Yoon, R. Srirambalaji and K. Kim, Chem. Rev., 2012, 112, 1196; J. Liu, L. Chen, H. Cui, J. Zhang, L. Zhang and C.-Y. Su, Chem. Soc. Rev., 2014, 43, 6011.

38 P. R. Schreiner, Chem. Soc. Rev., 2003, 32, 289.

39 A. G. Doyle and E. N. Jacobsen, Chem. Rev., 2007, 107, 5713.

40 Z. Zhang and P. R. Schreiner, Chem. Soc. Rev., 2009, 38, 1187.

41 S. Lancianesi, A. Palmieri and M. Petrini, Chem. Rev., 2014, 114, 7108.

42 S. V. Deshapande, C. C. Meredith and R. A. Pasternak, Acta Crystallogr., Sect. B: Struct. Crystallogr. Cryst. Chem., 1968, 24, 1396; For X-ray studies of self-association of urea structures, see: S. Stanković and G. D. Andreetti, Acta Crystallogr., Sect. B: Struct. Crystallogr. Cryst. Chem., 1978, 34, 3787; S. George, A. Nangia and V. M. Lynch, Acta Crystallogr., Sect. C: Cryst. Struct. Commun., 2001, 57, 777; S. George and A. Nangia, Acta Crystallogr., Sect. E: Struct. Rep. Online, 2003, 59, 901; A. M. Z. Slawin, J. Lawson, J. M. D. Storey and W. T. A. Harrison, Acta Crystallogr., Sect. E: Struct. Rep. Online, 2007, 63, 2925.

43 J. M. Roberts, B. M. Fini, A. A. Sarjeant, O. K. Farha, J. T. Hupp and K. A. Scheidt, J. Am. Chem. Soc., 2012, 134, 3334.

44 Different MOFs containing hydrogen-bond donors (primarily ureas) were synthesised before ref. 43; however, none of them were previously used as HBD catalysts.

45 For the pioneering work using urea, see: G. Dessole, R. P. Herrera and A. Ricci, Synlett, 2004, 2374.

46 M. J. Katz, Z. J. Brown, Y. J. Colón, P. W. Siu, K. A. Scheidt, R. Q. Snurr, J. T. Hupp and O. K. Farha, Chem. Commun., 2013, 49, 9449.

47 P. W. Siu, Z. J. Brown, O. K. Farha, J. T. Hupp and K. A. Scheidt, Chem. Commun., 2013, 49, 10920.

48 J. H. Cavka, S. Jakobsen, U. Olsbye, N. Guillou, C. Lamberti, S. Bordiga and K. P. Lillerud, J. Am. Chem. Soc., 2008, 130, 13850.

49 C. Palomo, M. Oiarbide and A. Mielgo, Angew. Chem., Int. Ed., 2004, 43, 5442; C. Palomo, M. Oiarbide and A. Laso, Eur. J. Org. Chem., 2007, 2561; Y. Alvarez-Casao, E. MarquésLópez and R. P. Herrera, Symmetry, 2011, 3, 220.
50 X.-W. Dong, T. Liu, Y.-Z. Hu, X.-Y. Liu and C.-M. Che, Chem. Commun., 2013, 49, 7681.

51 E. Dugan, Z. Wang, M. Okamura, A. Medina and S. M. Cohen, Chem. Commun., 2008, 3366.

52 S. Bernt, V. Guillerm, C. Serre and N. Stock, Chem. Commun., 2011, 47, 2838.

53 A. A. Tehrani, S. Abedi, A. Morsali, J. Wang and P. C. Junk, J. Mater. Chem. A, 2015, 3, 20408.

54 J. Li, P.-Z. Li, Q.-Y. Li, Y. Cao, H. Lu, H. Wu, F. Li, Y. Shi, X.-J. Wang and Y. Zhao, RSC Adv., 2014, 4, 53975.

55 X.-J. Wang, J. Li, Q.-Y. Li, P.-Z. Li, H. Lu, Q. Lao, R. Ni, Y. Shi and Y. Zhao, CrystEngComm, 2015, 17, 4632.

56 Y. Luan, N. Zheng, Y. Qi, J. Tang and G. Wang, Catal. Sci. Technol., 2014, 4, 925.

57 M. Kotke and P. R. Schreiner, Tetrahedron, 2006, 62, 434.

58 C. M. McGuirk, M. J. Katz, C. L. Stern, A. A. Sarjeant, J. T. Hupp, O. K. Farha and C. A. Mirkin, J. Am. Chem. Soc., 2015, 137, 919.

59 For the use of primary and secondary amines coordinated to the MOFs and acting through covalent interactions, see: M. Banerjee, S. Das, M. Yoon, H. J. Choi, M. H. Hyun, S. M. Park, G. Seo and K. Kim, J. Am. Chem. Soc., 2009, 131, 7524; D. J. Lun, G. I. N. Waterhouse and S. G. Telfer, J. Am. Chem. Soc., 2011, 133, 5806; W. Zhu, C. He, P. Wu, X. Wu and C. Duan, Dalton Trans., 2012, 41, 3072; P. Wu, C. He, J. Wang, X. Peng, X. Li, Y. An and C. Duan, J. Am. Chem. Soc., 2012, 134, 14991; T. Shi, Z. Guo, H. Yu, J. Xie, Y. Zhong and W. Zhua, Adv. Synth. Catal., 2013, 355, 2538; A. L. W. Demuynck, M. G. Goesten, E. V. Ramos-Fernandez, M. Dusselier, J. Vanderleyden, F. Kapteijn, J. Gascon and B. F. Sels, ChemCatChem, 2014, 6, 2211.

60 M. J. Ingleson, J. P. Barrio, J. Bacsa, C. Dickinson, H. Park and M. J. Rosseinsky, Chem. Commun., 2008, 1287; For examples of chiral Brønsted acid organocatalysts incorporated into the MOFs, see: M. Zheng, Y. Liu, C. Wang, S. Liu and W. Lin, Chem. Sci., 2012, 3, 2623; Z. Zhang, Y. R. Ji, L. Wojtas, W.-Y. Gao, S. Ma, M. J. Zaworotko and J. C. Antilla, Chem. Commun., 2013, 49, 7693; M. Lee, S. Min, S. N. Jeong and P. K. Thallapally, Dalton Trans., 2015, 44, 9349. 